\title{
Projeção de poder e intervenção militar pelos Estados Unidos da América
}

\author{
DOMÍCIO PROENÇA JÚNIOR* \\ ÉRICO E. DUARTE**
}

\section{Introdução}

A atuação internacional dos Estados Unidos da América admite diversas formas de relacionamento e intervenção. Uma das mais destacadas e únicas dessas alternativas de ação internacional reside em sua capacidade militar, isto é, na possibilidade de intervenção armada no desenrolar de um relacionamento político em escala mundial. Ainda que se possa querer tomar como indicador dessa capacidade de intervenção o acervo do poder dos Estados Unidos em termos gerais, a possibilidade de ação armada exige que se considere a dimensão propriamente tática, isto é, do uso da força no combate. Essa dimensão exige que se considere a organização humana, material e cognitiva pela qual se articulam unidades militares capazes de ação combatente, e como se sustentam essas capacidades ao longo do tempo.

Na medida em que se reconhece o papel único da capacidade militar dos Estados Unidos, essa questão se destaca das demais. Por um lado, o que os Estados Unidos são e não são capazes de fazer em termos combatentes, a que alcances desde suas posições de tempo de paz, e em que escala de tempo se torna uma variável chave, decisiva para quaisquer considerações de segurança. Por outro lado, quanto de força os Estados Unidos podem colocar em campo num determinado alcance, e num determinado tempo, é o insumo para a consideração adequadamente informada das possibilidades de recurso à força, seja na esperança do apoio dos Estados Unidos, seja em termos de avaliar a possibilidade de resistência à sua ação. Dada a centralidade da questão da segurança, e da possibilidade de recurso à força, no sistema internacional, a apreciação da capacidade de intervenção dos Estados Unidos e as especificidades de sua projeção de poder são essenciais para a consideração plena das Relações Internacionais, em particular para quaisquer estudos ou análises de Política Internacional.

Rev. Bras. Polít. Int. 46 (1): 135-152 [2003]

* Professor do Programa de Engenharia de Produção da Universidade Federal do Rio de Janeiro e Coordenador do Grupo de Estudos Estratégicos.

** Pesquisador do Grupo de Estudos Estratégicos. 
Nos últimos vintes anos, os Estados Unidos da América vêm re-arranjando a sua estrutura militar em resposta à mudança da percepção política dos cenários de possível emprego de força. O resultado desse processo foi o aumento paulatino de sua capacidade de intervenção militar. Esse aumento resultou de uma política de segurança nacional (national security policy; mais recentemente, por motivos retóricos, a national security strategy) que visava dar conta de crises regionais em áreas do mundo de seu interesse, de maneira pronta e decisiva. O principal resultado desse processo foi o estabelecimento de uma Força de Deslocamento Rápido (Rapid Deployment Force - RDF), originalmente pensada para a questão de resposta a uma crise anti-soviética no Golfo Pérsico, mas que evoluiu para um arcabouço de uso mais amplo ao longo do tempo. É por meio desse enquadramento que os Estados Unidos têm pensado, preparado e feito a projeção de força desde o fim da Guerra Fria ${ }^{1}$.

Este artigo tem como objetivo delinear sobre a estrutura dos Estados Unidos da América para intervenções militares como instrumento para projeção de seu poder no sistema internacional. Inicia-se pela apresentação do modelo conceitual que se adota para a análise do objeto do artigo - as forças de deslocamento rápido. Em segundo lugar, delineia a evolução histórica recente da capacidade de intervenção militar dos Estados Unidos e a Estratégia de Segurança Nacional (national security strategy) dos Estados Unidos na década de 1990. Em terceiro lugar, o artigo aborda as forças de deslocamento rápido (RDF), que constituem o principal conjunto de unidades combatentes para o papel de intervenção militar, considerando seus aspectos logísticos (a condição de possibilidade de criação, deslocamento e sustentação da força numa dada área de operações) e táticos (em termos do arcabouço humano, material e cognitivo, em particular, doutrinário, que orienta a existência de unidades militares específicas). Por fim, o artigo encerra com algumas observações sobre a utilidade da noção, e os contornos das necessidades, de forças de deslocamento rápido (rapid deployment forces) como parte coerente da política brasileira de defesa.

\section{Enquadramento conceitual}

Parte-se da definição de conceitos da relação entre projeção de poder e intervenção militar para a posterior análise dessa dinâmica sustentada pelos Estados Unidos.

A primeira definição a se fazer é que intervenção militar é invariavelmente guerra, ou seja, sempre é uma questão de política internacional resolvida por meio do uso da força como forma de um ator dobrar a vontade de um outro.

Existem diversas formas de projeção de poder no sistema internacional por um ator sobre outro ou sobre vários atores, sejam eles diplomáticos, comerciais ou militares. Intervenção militar, por sua vez, é uma forma de projeção de poder em que o objetivo político determina as metas, magnitude e duração de objetivos 
de engajamentos e operações de combate - conceito de tática - e a combinação de vários desses para um objetivo bélico que atenda ao propósito político de um ator - conceito de estratégia.

Uma intervenção militar, dentre as várias formas que pode assumir a guerra, requer obrigatoriamente o exercício da força de maneira física e presencial no território estrangeiro. Essa especificidade dá-se porque o objetivo político é apenas satisfeito pela conquista, sendo nesse caso a execução de uma estratégia militar persistente. O objetivo político pode ser ainda a coerção continuada no tempo para acúmulo de recursos de barganha na mesa de negociações ou devido a um objetivo que não é possível de ser destruído apenas ou simplesmente por bombardeios a longa distância. Nesse caso, tem-se uma estratégia militar incursiva.

Portanto, uma intervenção militar exige sempre uma expedição militar ou operação expedicionária. Isso se dá pelos aspectos políticos e estratégicos apontados, mas também por ser invariavelmente uma operação ofensiva. Tendo, como conseqüência, a propriedade intrínseca das desvantagens táticas e, principalmente, logísticas das formas de guerra em ataque em relação às formas de guerra em defensiva. Tal efeito denomina-se expedicionariedade e é objeto de análise em um artigo específico.

De qualquer maneira, essas colocações conceituais são satisfatórias para a melhor compreensão das análises que este artigo propõem e que se inicia por um breve resumo histórico da evolução da capacidade de intervenção militar dos Estados Unidos.

\section{Evolução histórica}

Após o término da Guerra do Vietnã, os Estados Unidos iniciaram a revisão de sua orientação estratégica na Guerra Fria. Desde o fim da II Guerra Mundial, tendo a União Soviética como contraste bipolar, os Estados Unidos entendiam a Europa Ocidental e o Extremo Oriente como as áreas em maior risco de confrontação. Por isso, deslocaram grande parte de suas forças para essas regiões. Com isso, julgavam ter o bloco ocidental/capitalista em segurança desde que a União Soviética não oferecia grande ameaça em termos navais. Outra conseqüência foi os Estados Unidos terem retrocedido em suas capacidades intervencionistas em países do Terceiro Mundo, substituindo-os por mecanismos de contrainsurgência, principalmente por meio de auxilio em termos de armamentos, treinamento e expertise militar a forças armadas de países aliados ou amigos.

Entretanto, o número de regiões em tensão aumentou na proporção que o Império Britânico era desconstruído no Oriente Médio, África e Ásia e ficavam sujeitas à influência do bloco socialista. ${ }^{2}$

Em 1979, a administração Carter apontou diretivas para que forças militares fossem organizadas para contingências em regiões remotas que pudessem fragilizar o equilíbrio de poder mundial. Em resposta, o Pentágono propôs a criação de um 
combinado de tropas das quatro forças singulares - Exército, Marinha, Força Aérea e Corpo de Fuzileiros Navais - para deslocamento rápido, sob a supervisão direta da Junta de Chefes de Estado-Maior (Joint Chiefs of Staff - JCS).

Ainda em 1979, o equilíbrio regional do Oriente Médio foi comprometido, sob os olhos norte-americanos com a queda do Xá do Irã. Tão grave quanto foi a invasão soviética ao Afeganistão no mesmo ano.

Em 1980, em regime de urgência, foi criada uma força-tarefa de forças integradas de deslocamento rápido (Rapid Deployment Joint Task Force - RDJTF). Em 1983, o RDJTF alcançou o status de um comando unificado de combate pleno denominado Centcom (Central Command - Comando Central). Ele possui como delimitação geográfica: Egito, Sudão, Djibouti, Etiópia, Somália, Quênia, Afeganistão, Bahrain, Irã, Iraque, Kuwait, Omã, Paquistão, Yemen, Qatar, Arábia Saudita e Emirados Árabes ${ }^{3}$.

O principal cenário de combate do sistema RDF, durante a década de 1980, era responder a uma invasão soviética ao Irã (Plano Nacional de Guerra $1002)^{4}$. A partir de 1988, houve uma mudança de orientação para um conflito de alta intensidade contra o Iraque. Essa mudança foi baseada na vertiginosa diminuição das forças soviéticas por Gorbachev e em decorrência da constatação pelos Estados Unidos de que a maior preocupação dos lideres árabes era o governo de Saddam ${ }^{5}$. Esse cenário persistia mesmo após a guerra contra o Iraque em 1990-1991.

Figura 1

Área de atuação do Centcom

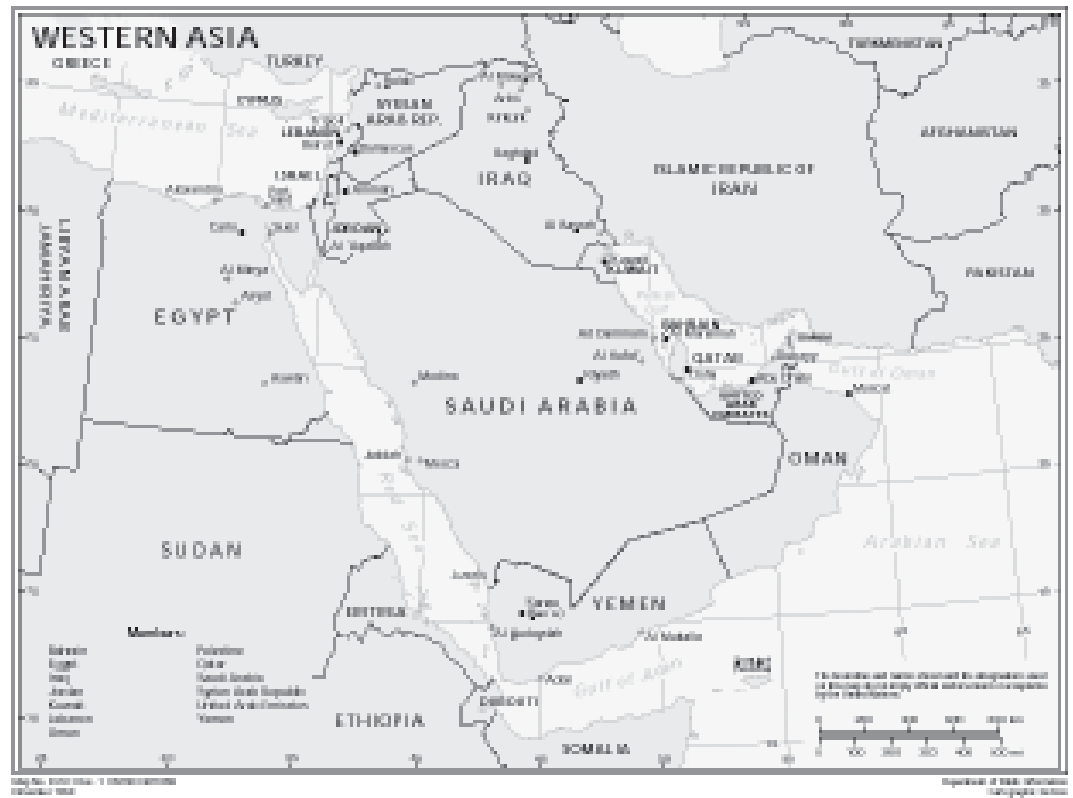

Fonte: www.worldmaps.org 
Entretanto, desde meados da década de 1980, houve também a atuação de forças de deslocamento rápido dos Estados Unidos em outras regiões do globo, como: Filipinas, Camboja, Kosovo, Moçambique, Haiti, Angola, Panamá, Nicarágua e El Salvador. A partir de então, forças de deslocamento rápido passaram a ser uma atribuição funcional - organização de forças para ações de contingência dos comandos unificados de combate de atribuição geográfica dos Estados Unidos : Pacífico, Sul, Europeu e Norte, além do Central.

\section{A Estratégia de Segurança Nacional dos Estados Unidos na década de 1990}

A Estratégia de Segurança Nacional (National Security Strategy) dos Estados Unidos durante o governo Clinton (1993-2000) ${ }^{6}$ orientou o engajamento dos recursos de poder em assuntos internacionais de maneira a permitir o alargamento da comunidade internacional formado por países estáveis, orientados pela lógica de mercado e constituídos por regimes democráticos ${ }^{7}$.

Os meios militares - assim como os diplomáticos e econômicos - seriam empregados com o objetivo de moldar o ambiente internacional para concretização dessa orientação governamental.

As forças armadas dos Estados Unidos realizavam a consecução dessa política mediante três orientações estratégicas. Primeiro, elas atuavam de forma a promover a estabilidade de regiões de importância para os Estados Unidos e países aliados ou amigos. Segundo, buscavam prevenir conflitos e ameaças, limitando a difusão de tecnologias militares, combatendo ameaças transnacionais e provendo a garantia de proteção a países aliados ou amigos. Buscavam, ainda, em terceiro, moldar o ambiente internacional detendo agressões e coerções em regiões-chave do mundo ${ }^{8}$.

Em termos das forças armadas, essa estratégia nacional orientou o planejamento e preparo para dois conflitos regionais de grande intensidade (Major Regional Conflict - MRC) em duas regiões do mundo: no Golfo Pérsico e na Península Coreana. A possibilidade de emprego militar ainda era prevista na conduta de operações de contingência para contenção e resolução de crises que gerassem desdobramentos negativos aos Estados Unidos e seus países aliados e amigos, onde quer que eles tivessem lugar ${ }^{9}$. Essa adequação das forças é constantemente apontada como preparo para todo o "espectro de intensidade de conflitos".

Por isso, o aparato militar dos Estados Unidos sustentava uma capacidade de projeção de força intercontinental sem igual. Unidades militares eram posicionadas permanentemente em bases terrestres fora dos Estados Unidos, deslocadas e disponibilizadas em alto mar e ocasionalmente deslocadas para exercícios, treinamento combinado ou interações com outras forças militares ${ }^{10}$. É dessa forma que eles têm sustentado o seu sistema de forças de deslocamento rápido.

As forças de deslocamento rápido são um real instrumento de política de segurança e externa dos Estados Unidos. Como se estabelece essa instrumentalização 
política do sistema RDF e os planejamentos de ação militar de cada uma das forças que o integra são tratados no item a seguir.

\section{As Forças de Deslocamento Rápido dos Estados Unidos}

Essas unidades militares foram organizadas a partir da última década da Guerra Fria, a fim de conter crises na região do Oriente Médio, África e Sudoeste Asiático que pudessem ameaçar o bloco ocidental dentro do contexto de confronto bipolar. O sistema RDF originou a criação do Comando Unificado Central (US Central Command - Centcom). Esse possuía a atribuição estratégica de coordenar operações de forças integradas numa ampla região do globo - da porção oriental do continente africano ao Afeganistão ${ }^{11}$. No entanto, a demanda por rápida ação armada pelos Estados Unidos na América Central (Panamá, em 1989), região do Pacifico (Filipinas, em 1990) e Europa (ex-Iugoslávia, várias vezes na década de 1990) elevou forças de deslocamento rápido a um conceito de integração de forças com capacidades específicas e uma atribuição funcional de todos os comandos unificados de combate. Cada comando unificado de combate de atribuição geográfica dos Estados Unidos - Pacífico, Sul, Europeu e Norte, além do Central - também são responsáveis pela integração e coordenação das unidades mais capacitadas a deslocarem unidades combatentes para contingências em suas respectivas regiões intercontinentais de atuação $0^{12}$.

Essas unidades são designadas a partir das quatro forças singulares dos Estados Unidos: Corpo de Fuzileiros Navais, Marinha, Exército e Força Aérea, classificadas em três categorias de capacidades. Uma primeira categoria de unidades de resposta rápida de uma semana: as Unidades Expedicionárias de Fuzileiros, Capacitadas a Operações Especiais [Marine Expeditionary Forces (Special Operations Capable) - MEU(SOC)] do Corpo de Fuzileiros Navais (US Marine Corps) e as Brigadas em Prontidão da $82^{\mathrm{a}}$ Divisão Aeroterrestre (82nd Airborne Division Ready Brigade - DRB) do Exército dos Estados Unidos.

A segunda categoria de forças de contingência é formada por divisões ${ }^{13}$ inteiras, capazes de deslocamento entre trinta a sessenta dias: a $3^{\text {a }}$ Divisão de Infantaria Mecanizada, a $10^{\mathrm{a}}$ Divisão de Montanha, o $2^{\mathrm{o}}$ Regimento de Cavalaria Blindada e a $101^{\text {a }}$ Divisão de Assalto Aéreo do XVIII Corpo-de-Exército Aeroterrestre $^{14}$. Dentro dessa categoria, incluem-se ainda as três Forças Expedicionárias de Fuzileiros Navais (Marine Expeditionary Forces - MEF). Uma MEF, por sua vez, é capaz de deslocar um destacamento de vanguarda Marine Expeditionary Force (Forward), MEF(Fwd) - para enfrentamento de crises entre sete e quinze dias, sendo uma alternativa de força intermediária entre as duas categorias mencionadas. 


\section{Figura 2}

\section{Estrutura geral do sistema de Forças de Deslocamento Rápido dos Estados Unidos.}

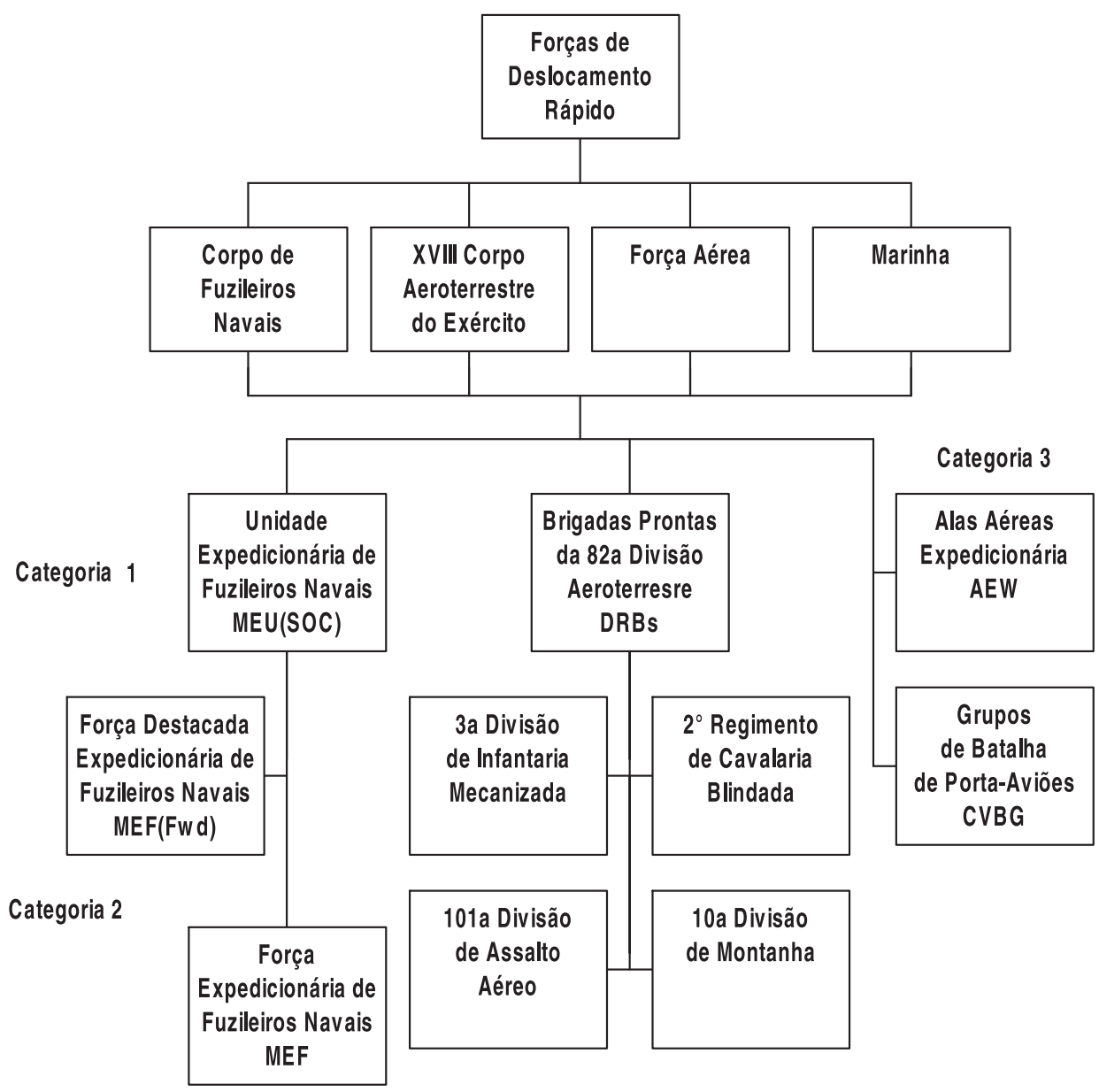

Dados: ESHEL, David. The US Rapid Deployment Forces. New York: ARCO, 1984; e www.globalsecurity.org 
A terceira e última categoria do sistema RDF é formada pelas alas aéreas expedicionárias (Aerospace Expedicionary Wing - AEW) da Força Aérea e os grupos de batalha de porta-aviões (Aircract Carriers Battle Groups - CVBG) da Marinha dos Estados Unidos para apoio logístico, transporte e apoio de fogo $0^{15}$. A Força Aérea dos Estados Unidos tem rápida capacidade de resposta no atendimento do transporte estratégico das tropas e equipamentos do US Marine Corps e do XVIII Corpo, assim como a disponibilização de esquadrões de caças para escolta desse deslocamento aéreo num prazo de dias.

Entretanto, o deslocamento de grupos de aviões de combate para apoio a operações de contingência no estrangeiro depende da existência de pistas de pouso, munição, suprimento e combustível em países aliados ou amigos. Na Guerra do Golfo de 1990-1991, a Força Aérea foi capaz de deslocar em trinta e seis horas o $1^{\circ}$ Esquadrão Tático de Combate composto por quarenta e oito caças F-15C da Base Aérea de Langley, na Virgínia, para aeroportos na Arábia Saudita. Entretanto, esse foi um caso atípico devido a exercícios conduzidos um mês antes conjuntamente com a Força Aérea Saudita, sendo mantido secretamente setenta e dois aviões de reabastecimento aéreo KC-135. Além disso, os aeroportos da Arábia Saudita ofereciam toda a infra-estrutura e logística necessária especificamente para as aeronaves norte-americanas ${ }^{16}$.

Os CVBGs cooperam provendo aviões de combate, apoio de fogo naval e de mísseis. Seu deslocamento para uma costa de uma área em crise leva um tempo relativamente longo de duas semanas ou mais. Esses agrupamentos navais geralmente são posicionados em áreas oceânicas e sua aproximação a litorais depende de um cuidadoso plano de reconhecimento e deslocamento em escalão dos navios de combate que os compõem. Na Guerra do Golfo de 1990-1991, os primeiros navios de combate da Marinha dos Estados Unidos posicionaram-se para o embargo naval ao Iraque quatorze dias após a notificação ${ }^{17}$.

A seguir, é conduzido um estudo mais detalhado do sistema de forças de deslocamento rápido dos Estados Unidos, segundo suas condições de possibilidade logística e aspectos táticos.

\section{Considerações logísticas sobre Forças de Deslocamento Rápido ${ }^{18}$}

As forças de deslocamento rápido são formadas por soldados profissionais e condicionadas dentro do mais alto nível de treinamento. Elas são habilitadas nas várias formas de armas combinadas, como também na capacidade de forças integradas.

A mobilidade estratégica e a sustentação das forças de deslocamento rápido dos Estados Unidos envolvem tanto meios aéreos e navais como um sistema logístico híbrido de forças pré-dispostas ${ }^{19}$. 
Os meios aéreos são os mais capazes de deslocamento rápido. No entanto, essa capacidade passa a ser constrangida em proporção ao tempo que as operações são prolongadas. Isso decorre da capacidade de carga dos meios aéreos ser mais limitada, o que resulta numa força deslocada com uma quantidade de suprimento orgânico insuficiente para longos períodos de operação e, por isso, dependente de re-abastecimento. Outro aspecto importante dos meios aéreos de transporte é o seu rápido desgaste devido a pausas, necessariamente, cada vez mais longas para manutenção das aeronaves. Com o acúmulo de horas de vôo, é necessária uma revisão cada vez mais cuidadosa e extensa de peças hidráulicas, turbinas e até fuselagem devido à fadiga de material.

Como resultado, com exceção de operações de segurança de pequeno porte, forças deslocadas por meios aéreos requerem a disponibilidade de bases logísticas terrestres avançadas protegidas para composição e sustentação das forças deslocadas. Essas condições de possibilidade logística são próprias da $82^{\mathrm{a}}$ Divisão Aeroterrestre e da $101^{a}$ Divisão de Assalto Aéreo (sendo que nessa, apenas a $1^{\text {a }}$ Brigada é aerotransportável e o restante de suas forças deve seguir em navios).

A mobilidade de forças por meios navais possui um tempo de resposta mais limitado, mas um potencial de sustentação muito maior. Por outro lado, o apoio tático e logístico possível de ser provido pela Marinha dos Estados Unidos possibilita uma menor dependência em bases terrestres e, quando necessárias, uma maior capacidade de composição, proteção e sustentação das mesmas. A utilização desses meios logísticos é prevista em cenários de média intensidade ou de guerra contra o Iraque ou Coréia do Norte.

A maior parte do material bélico das demais unidades do XVIII Corpo é transportada por meios navais. Uma variação importante são as MEU(SOC)s do US Marine Corps. Elas são dispostas num sistema de rotação permanente em alto-mar nas regiões dos hemisférios ocidentais e orientais.

O terceiro sistema logístico para projeção de força dos Estados Unidos é o sistema de forças pré-dispostas em bases avançadas. As tropas e o material bélico leve são deslocados por meios aéreos a partir dos Estados Unidos e o material bélico pesado transportado por meios navais a partir de esquadrões navais pré-dispostos em bases navais avançadas ou em bases terrestres de países aliados ou amigos. Esse sistema permite a união tanto das características de responsividade dos meios de mobilidade aérea, mas mantendo uma capacidade de transporte e de sustentação das forças deslocadas por meios navais. Por isso, associado a um custo mais acessível, possibilita restrições menos severas ao poder combatente por meio de uma maior liberdade na composição força-combatente em função dos cenários de conflito ${ }^{20}$. 


\section{Figura 3 \\ Bases avançadas de pré-disposição de material bélico das Forças Armadas dos Estados Unidos}

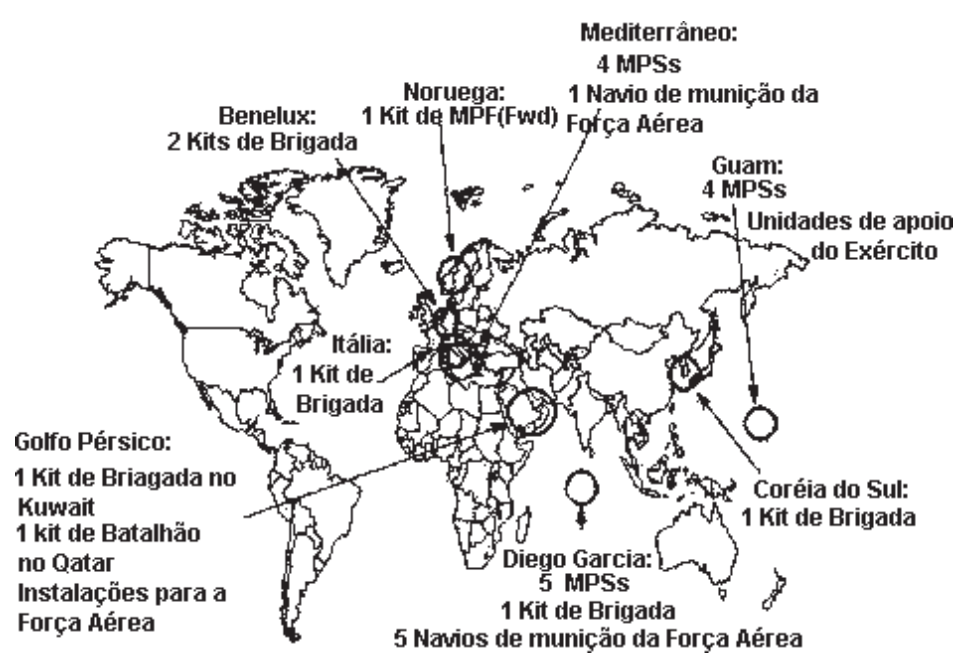

Fonte: Editada pelo autor de US CONGRESSIONAL BUDGET OFFICE. Moving US forces: options for strategic mobility. Washington: US Congress, 1997.

Apesar de o Exército dos Estados Unidos possuir a maior parte de suas forças movidas e sustentadas por meios aéreos e navais, ele possui disponível material bélico para uma brigada de divisão pesada como a $3^{\text {a }}$ Divisão de Infantaria Mecanizada ou o $2^{\circ}$ Regimento de Cavalaria em bases terrestres na região do Benelux, Itália, Kwait, Coréia do Sul e na base naval de Diego Garcia no Oceano Índico; além de unidades de apoio na base naval de Guam no Pacífico.

O Corpo de Fuzileiros Navais possui o mesmo sistema logístico. É prédisposto material bélico suficiente para uma $\operatorname{MEF}(\mathrm{Fwd})$ por meio de esquadrões de navios de pré-disposição marítima (Maritime Prepositioning Ships - MPS) em bases navais avançadas no Mar Mediterrâneo, Guam no Oceano Pacífico e Diego Garcia no Oceano Índico. Na Noruega, desde a década de 1970, possui equipamento para constituição de uma $\operatorname{MEF}(\mathrm{Fwd})$. A Força Aérea possui instalações para bases expedicionárias no Qatar, Kuwait e Arábia Saudita. Possui ainda navios carregados com munições para seus aviões de combate no Mediterrâneo e em Diego Garcia.

Essa disposição de material bélico, além de ser orientada a resposta de crises em qualquer parte do globo, é uma forma de reestruturação do aparato bélico dos Estados Unidos no pós-Guerra Fria. A disposição de material bélico do Exército conjuntamente com as duas divisões que estão dispostas na Europa, por exemplo, substituem os dois Corpos-de-Exército blindados que existiam lá até o 
fim da década de 1980. O mesmo pode se dizer sobre o kit para formação de uma $\operatorname{MEF}(F w d)$ na Noruega.

Essas condicionantes logísticas não são um fim em si mesmas. Elas são gerenciadas a fim de respaldar as capacidades táticas necessárias ao cumprimento das atribuições estratégicas das forças de deslocamento rápido. Os cenários de aplicação tática das unidades que as conformam são apresentadas a seguir.

\section{Considerações táticas sobre Forças de Deslocamento Rápido}

A atribuição de cenários de conflitos a unidades militares é bastante clara dentro do sistema RDF. As alas aéreas da Força Aérea e os grupos de batalha de porta-aviões da Marinha possuem atribuições de apoio tático e logístico; e o XVIII Corpo Aeroterrestre e o Corpo de Fuzileiros Navais, a atribuição principal das operações terrestres.

A força do Exército dos Estados Unidos para operações de contingências é o XVIII Corpo Aeroterrestre. Os cenários de ação em cenários de baixa intensidade são operações de segurança pela $82^{a}$ Divisão Aeroterrestre, principalmente por meio das DRBs ${ }^{21}$.

Em caso de operações de média intensidade, as outras unidades do XVIII Corpo podem ser dispostas tanto com a função de reforço de tropas já deslocadas, como de vanguarda do contingente de contra-golpe em mobilização e formação e de condução de uma campanha terrestre independente. Em cenários de alta intensidade, o XVIII Corpo como um todo tem a função de contenção a uma força invasora a um país amigo ou aliado, cuja contra-resposta será por meio do reforço de divisões ou Corpos-de-Exército blindados do Exército dos Estados Unidos ${ }^{22}$.

O Corpo de Fuzileiros Navais é uma organização única dos Estados Unidos com função de operações aero-anfíbias em qualquer tipo de contingência, em integração com as unidades do XVIII Corpo do Exército, com forças armadas de países aliados ou independentemente. Sua principal unidade de deslocamento rápido são as MEU(SOC)s (Marine Expeditionary Units, Special Operations Capable - Unidade Expedicionária de Fuzileiros Navais) ${ }^{23}$. Em situações de crises, o US Marine Corps pode enviar ainda uma MEF(Fwd) (Marine Expeditionary Force, Forward - Força Destacada Expedicionária de Fuzileiros Navais). Ela é empregada em cenários de baixa intensidade para reforço de uma MEU(SOC)s ou DRB ou como única unidade de resposta rápida. Em cenários de média intensidade uma MEF(Fwd) pode ser a vanguarda dos contingentes do XVIII Corpo de uma ou mais MEFs (Marine Expeditionary Force - Força Expedicionária de Fuzileiros Navais). As MEFs são aplicadas na resolução de crises de média intensidade e como força de contenção ao lado do XVIII Corpo Aeroterrestre.

Numa perspectiva de ação integrada, essas forças são orientadas à resolução de contingências. As principais contingências consideradas são: garantir o cumprimento de acordos e soluções diplomáticas, como cessar-fogo ou eleições 
livres; obtenção e controle de objetivos físicos chave como portos, aeroportos, áreas industriais e centros políticos, negando seu uso pelo inimigo; controle de áreas urbanas; operações constabulares; proteção e resgate de cidadãos norteamericanos; contenção de guerras civis ou conflitos sub-regionais; prover ajuda humanitária e assistência em caso de desastres ${ }^{24}$.

Um outro cenário de atuação de forças de deslocamento rápido é atuar como força de contenção a invasões ou agressões a países aliados ou amigos dos Estados Unidos no Golfo Pérsico e na Península Coreana. Assim, as forças de deslocamento rápido não são preparadas ou orientadas a conduzirem qualquer dos dois conflitos regionais de grandes proporções (Major Regional Conflict MRC). Elas são designadas a efetuarem um primeiro combate de contenção. Tal atribuição tem a denominação de halt-phase ("alto de parada") ou half-war (meia guerra). Sendo que o enfrentamento propriamente dito será conduzido na composição com outras unidades das forças armadas dos Estados Unidos ${ }^{25}$. Na Guerra do Golfo em 1990-1991, o XVIII Corpo e a I MEF atuaram com o VII Corpo Blindado, disposto, na época, na Alemanha.

Apesar dos cenários de MRC, a resposta a contingências de baixa intensidade é o mais freqüente cenário de emprego de RDF. Com isso, as principais unidades do sistema de forças de deslocamento rápido são as MEU(SOC)s do US Marine Corps e as DRBs da 82 ${ }^{a}$ Divisão Aeroterrestre (ver gráfico 1 a seguir). Uma MEF(Fwd) ou uma brigada de Exército podem ser deslocadas em até uma semana dependendo da disponibilidade de material pré-disposto por meio de esquadrões marítimos.

\section{Gráfico 1 \\ Intervalos de deslocamento médios de unidades de forças terrestres dos Estados Unidos}

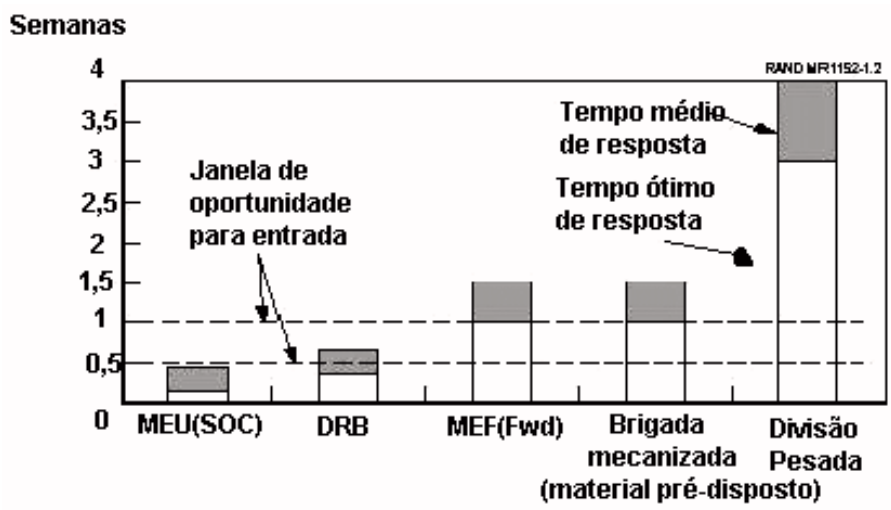

Unidade

Fonte: Editado pelo autor de GRITTON, Eugene et al. Ground forces for rapidly employable joint task force. Santa Monica: Rand, 2000, p. 13. 
As MEU(SOC)s e as DRBs são as unidades de deslocamento mais rápido, por isso mais capazes de aproveitar a fase de uma contingência em que existe a oportunidade de fazer frente a uma força inimiga antes que ela tenha tomado posições consolidadas. Esse planejamento visa a aumentar as chances de sucesso tático de uma unidade de deslocamento rápido, principalmente em cenários de halt-phase, não cedendo ao inimigo a vantagem tática de uma posição defensiva. Por outro lado, as MEU(SOC)s e DRBs são capazes de entrada forçada por meio de suas respectivas capacidades de assalto anfíbio e aeroterrestre ${ }^{26}$. Em cenários em que não existe a disponibilidade de bases aéreas e portos, sob o poder de defesas inimigas, essas capacidades são o único recurso ${ }^{27}$.

\section{Considerações finais}

A apresentação dos contornos políticos, logísticos e táticos das Forças de Deslocamento Rápido dos Estados Unidos corresponde ao desenho geral de sua capacidade de intervenção armada em escala mundial. Atende, assim, aos propósitos de informar e orientar com relação aos requisitos, possibilidades e limites da intervenção armada de parte dos Estados Unidos. Além disso, porém, é oportuno que se reconheça como o esforço dos Estados Unidos e de suas forças armadas produziu, igualmente, uma referência para os que se disponham a considerar as necessidades militares da resposta rápida.

Uma expressão sintética das metas da política de defesa nacional na Gestão Quintão (1999-2002) corresponderia à posse de forças de resposta rápida, marcadas pelas qualidades da versatilidade, sustentabilidade e interoperabilidade ${ }^{28}$. O problema colocado pelo Ministro da Defesa é, mantidas as proporções, o mesmo problema dos Estados Unidos. Num sentido muito pragmático, pode mesmo ser um problema comum a todas as política de defesa. Trata-se da construção, e sustentação no tempo, de capacidade militar de resposta pronta a uma determinada contingência em que o uso de força armada possa ser oportuno ou útil.

A experiência da Força de Deslocamento Rápido dos Estados Unidos serve, assim, para apontar ainda uma possível agenda de pesquisa, em prol da identificação dos requisitos, prioridades, necessidades e alternativas para a constituição das forças armadas brasileiras para o Século XXI. Trata-se de identificar a utilidade da noção de forças de deslocamento rápido, enraizandoa e emprestando-lhe especificidade para a situação logística, e as demandas táticas brasileiras, como insumo para o processo de tomada de decisão e subsídios para a formulação da Política de Defesa. 


\section{Notas}

1 A fonte descritiva mais completa de RDF é ESHEL, David. The US Rapid Deployment Forces. New York: ARCO, 1985. Um registro pessoal de sua criação está presente em QUILAN, David. The role of the Marine Corps in Rapid Deployment Forces. Washington: National Defense University Press, 1983. As discussões mais atuais encontram-se em MATSUMARA, John et al. Lightning over water. Santa Monica: RAND, 2000; GRITTON, Eugene et al. Ground forces for a rapid employable joint task force. Santa Monica: RAND, 2000; e Congressional Budget Office. Moving US forces: options for strategic mobility. Washington: Congress of United States, 1997.

2 ESHEL, David. US Rapid Deployment Forces. New Yoirk: ARCO, 1985, p. 55-61 e QUILAN, David. The role of the Marine Corps in Rapid Deployment Forces. Washington: National Defense University Press, 1983.

3 ESHEL, David. US Rapid Deployment Forces. New Yoirk: ARCO, 1985, p. 55-61 e HINES, Jay. "From Desert One to Southern Watch: the Evolution of US Central Command". Joint Forces Quarterly. Washington. Spring, 2000, p. 42-49.

$4 \quad$ Esse plano se baseava na contenção das forças soviéticas nas Montanhas Zagros, na fronteira entre o Irã e a União Soviética, aplicando as forças de deslocamento rápido conjuntamente com aviões de ataque da Força Aérea dos Estados Unidos. Esse plano é detalhado em BLACKWELL, James. Thunder in the desert. New York: Bantam Books, 1991, p. 81-82. HINES, Jay. "From Desert One to Southern Watch: the Evolution of US Central Command". Joint Forces Quarterly. Spring, 2000, p. 42-49.

6 Anualmente, o Executivo dos Estados Unidos produz documentos quanto à estratégia de segurança nacional e à disposição de suas forças em relação a ela. As considerações políticas e estratégicas realizadas nesta dissertação são baseadas no último documento executivo da administração Clinton: COHEN, William. Annual report of Department of Defense to the President and the Congress. Washington: Office of Secretary of Defense, 2001. COHEN, William. Annual report to the President and the Congress. Washington: Office of Secretary of Defense, 2001, p. 4 COHEN, William. Annual report to the President and the Congress. Washington: Office of Secretary of Defense, 2001, p. 4.

9 COHEN, William. Annual report to the President and the Congress. Washington: Office of Secretary of Defense, 2000, p. 8-9.

10 COHEN, William. Annual report to the President and the Congress. Washington: Office of Secretary of Defense, 2000, p. 5-7 e p. 20-21.

11 HINES, Jay. "From desert one to southern watch: the evolution of US Central Command". Joint Forces Quarterly. Spring, 2000, p. 42-49.

12 Cabe explicitar que a estrutura integrada de comando e planejamento militar dos Estados Unidos possui dois canais funcionais. A Junta de Chefes de Estado-Maior (Joint Chiefs of Staffs - JCS) tem a função de planejamento integrado, a outra parte da estrutura é composta por comandos unificados (Unified Commands). Esses coordenam a ação integrada em regiões específicas do globo, já citadas, ou de integração em atividades específicas, como o de transporte, forças especiais e armamento nuclear. Ver COHEN, William. Annual report to President and the Congress. Washington: Office of the Secretary of Defense, 2001, p. 29-39. A estrutura integrada de comando e planejamento tem como atribuição a elaboração de planos de ação para as diversas ações militares. Na realidade da guerra moderna, quase que invariavelmente essas ações exigiram a coordenação de duas ou todas as forças singulares por meio de um conjunto de aparatos que permita a ação integrada das forças aéreas, navais e terrestres Essa coordenação não é simples e exige a prática de um planejamento integrado. Não apenas para propiciar doutrina, mas também treinamento e projeto de força convergentes. Da mesma 
forma, também avança a implementação de programas que não são específicos de nenhuma força, porém que agregam ao aparato bélico nacional como um todo (tecnologia nuclear, por exemplo).

13 Divisão é a maior organização tática de um exército. No caso dos Estados Unidos, uma divisão é treinada a combater como um time de armas combinadas e são capazes de conduzir batalhas e engajamentos independentemente, por um tempo significativo. O Exército dos Estados Unidos possui dez divisões ativas: quatro da Europa, uma na Coréia do Sul, uma no Havaí e seis nos Estados Unidos. Dessas seis, quatro constituem o XVIII Corpo, o que reflete o seu papel prepoderante em tempos ausentes de conflitos de alta intensidade. Ver www.globalsecurity.org/agencies/army.htm.

14 ESHEL, David. The US Rapid Deployment Forces. New York: ARCO, 1984.

15 ESHEL, David. The US Rapid Deployment Forces. New York: ARCO, 1984

16 BLACKWELL, James. Thunder in the desert. New York: Bantam Books, 1991, p. 93-95.

17 BLACKWELL, James. Thunder in the desert. New York: Bantam Books, 1991, p. 95-96.

18 Logística é dinâmica relacionada aos requerimentos materiais da força, a saber: suprimentos disponíveis e esperados, organização e administração, transporte e linhas de abastecimento. A logística é a dinâmica mais crítica para qualquer força e a mais susceptível a erros. Ela é também a que conecta a sociedade e às forças armadas no contexto industrial da guerra contemporânea. Logística é, portanto, uma série de bens e serviços que resultam não apenas na materialização das forças, mas que proporcionam a capacidade suficiente para o emprego dessas segundo os ditames políticos e as características próprias dos meios. CREVELD, Martin van. Suppliyng war. New York: Cambridge Press, 1977, p. 1-4; e DINIZ, Eugenio \& PROENÇA Jr., Domício. Política de defesa no Brasil. Brasília: Editora da UnB, 1998, p. 66-67.

19 A descrição mais detalhada do sistema de mobilidade dos Estados Unidos está em COHEN, William. Annual report to the President and Congress. Washington: Office of the Secretary of Defense, 2001, p. 63-67. A discussão sobre a mobilidade estratégica e sua sustentação em cenários intercontinentais encontra-se em US CONGRESSIONAL BUDGET OFFICE. Moving US forces: options for strategic mobility. Washington: US Congress, 1997. Ver BETAQUE, Norma (org.). Naval expeditionary logistics. Washington: National Research Council, 1998.

Operações de segurança resumem-se à tomada e retenção de objetivos físicos ou áreas limitadas. Pode ser tanto para finalidade de uma missão ou para abertura de entrada forçada para forças em uma campanha terrestre ou aérea. US Army. FM 90-26 Airborne Operations. Washington: Department of Army, 1990, capítulo 1, (www.globalsecurity.org).

COHEN, William. Annual report to the President and the Congress. Wasshington: Office of the Secretary of Defense, 2001, p. 61.

23 COHEN, William. Annual report to the President and the Congress. Washington: Office of the Secretary of Defense, 2001, p. 62-63.

24 US Marine Corps. MCDP-3: Expeditionary Operations. Washington: HQ/USMC, 1998, p. 37-38.

25 GRITTON, Eugene et al. Ground forces for Rapidly Joint Task Deployment Forces. Santa Monica: Rand, 2000, p. XX e HINES, Jay. "From Desert One to Southern Watch: the Evolution of US Central Command”. Joint Forces Quarterly. Spring, 2000, p. 42-49. Para uma fonte oficial, ver: COHEN, William. Annual report to Congress. Washington: Office of the Secretary of Defense, 2001, p. 22-23. Monica: Rand, 2000, p. 14-18.

27 US Marine Corps. MCDP.3: Expeditionary Operations. Washington: HQ/USMC, 1998, p. 40-41 e US Army. FM 90-26: Airborne Operations. Washington: Department of Army, 1990, capitulo 1, (www.globalsecurity.org). 
28 QUINTÃO, Geraldo Magela. Pronunciamento do Ministro da Defesa quando da sessão de abertura do Seminário Diálogo Brasil-Alemanha. Rio de Janeiro: Centro de Estudos das Américas/UCAM, Grupo de Estudos Estratégicos/Coppe/UFRJ, 21 a 23 de Setembro de 2001. Uma versão desse texto está em: QUINTÃO, G. M. et al. Segurança e Soberania. Rio de Janeiro, Fundação Konrad Adenauer, 2002.

\section{Bibliografia}

ASPIN, Les. Defense for a New Era: lessons of the Gulf War. Washington: House of Representatives, 1992.

BETAQUE, Norma et al. Naval Expeditionary Logistics. Washington: National Research Council, 1998.

BLACKWELL, James. Thunder in the desert. New York: Bantam Books, 1991.

BROWN, James. “In search of synergy: Joint Amphibious/Air Assault Operations”. Joint

Forces Quarterly. Washington: Joint Forces College. Winter, 1999, p. 48-52.

BUSH, George. National Security Directive 45. Washington: White House, 1990.

BUSH, George. National Security Directive 54. Washington: White House, 1991.

BYMAN, Daniel \& WOXMAN, Matthew. Confronting Iraq: US policy and the use of force since the Gulf War. Santa Monica: RAND, 2000.

CLANCY, Tom. Marine. New York: Berkley Books, 1996.

CLANCY, Tom. Airborne. New York: Berkley Book, 1997.

CLAUSEWITZ, Carl von. Campagne de 1814. Paris: Ivrea, 1993.

CLAUSEWITZ, Carl von. On war. New York: Everyman’s, 1993.

CONDON, John. “The Marine Air-Ground Team at Chosin Reservoir”. Joint Forces Quarterly. Washington: Joint Forces College. Summer, 2001, p.47-52.

CONGRESSIONAL BUDGET OFFICE. Moving US forces: options for strategic mobility. Washington: US Congress, 1997.

CORBETT, Julian. Some principles of maritime strategy. Annapolis: Naval Institute Press, 1988.

CORDESMAN, Anthony H. \& WAGNER, Abraham R. The lessons of modern war: the Gulf War. Boulder: Westview Press, 1996.

DEPARTMENT OF DEFENSE. Conduct of the Persian Gulf War: final report to the Congress. Washington: Office of Secretary of Defense, 1992.

DINIZ, Eugenio. Clausewitz, balanço ataque-defesa e a teoria das Relações Internacionais. Rio de Janeiro: Coppe/UFRJ, 2002.

DOUGHERTY, Donald. “The Evolution of Air Assault”. Joint Forces Quarterly. Washington: Joint Forces College. Spring, 1999, p. 51-58.

DUNNIGAN, James \& BAY, Austin. From shield to storm. New York: Authors Choice Press, 1992.

ESHEL, David. The US Rapid Deployment Forces. New York: ARCO, 1984.

FRIEDMAN, Norman. Desert victory. Annapolis: Naval Institute Press, 1991.

GRITTON, Eugene et al. Ground forces for a Rapid Employable Joint Task Force. Santa Monica: RAND, 2000.

HINES, Jay. "From Desert One to Southern Watch: the Evolution of US Central Command”. Joint Forces Quarterly. Washington: Joint Forces College. Spring, 2000, p. 42-49. 
HOOKER, Richard. “The Airborne Division in 2010”. Military review, Maio-Junho, 2001, p. 83-87.

KAZMIERSKI, Michael. US army power projection in the 21st century. Fort Leavenworth: US Army Command and General Staff College, 1990.

KRULAK, Charles. Maritime prepositioning force 2010 and beyond. Washington: HQ/ US Marine Corps, 1997.

MAHNKEN, Thomas \& WATTS, Barry. "What the Gulf War Can (and Cannot) Tell Us about the Future of Warfare”. International security. Boston: MIT Press. 22(2), 1997, p. 151-162.

MATSUMARA, John et al. Lightning over water. Santa Monica: RAND, 2000.

PAGONIS, William. Moving mountains. Boston: Harvard Business School Press, 1992.

PROENÇA Jr., Domício \& DINIZ, Eugenio. Política de defesa no Brasil: uma análise crítica. Brasília: Ed UnB, 1998.

Páginas da Internet

www.defenselink.mil

www.dtic.mil/doctrine.htm

www.fas.org/man

www.geocites.com/Pentagon/5265

www.geocites.com/Pentagon/7963/airbornewarfare.htm

www.globalsecurity.org

www.gwu.edu/ nsarchiv

www.rand.org

Resumo

O artigo analisa a projeção de poder pelos Estados Unidos por meio de intervenções militares a partir de um enquadramento conceitual, seguida de uma revisão histórica da formação do sistema de Forças de Deslocamento Rápido até a Estratégia de Segurança Nacional dos Estados Unidos na década de 1990. $\mathrm{O}$ artigo realiza ainda um estudo mais detalhado dos aspectos táticos e logísticos dessas forças que compõem a capacidade de intervenção militar dos Estados Unidos. Por fim, ele aponta a utilidade desse estudo para a formulação da política de defesa do Brasil.

\section{Abstract}

This article describes United States power projection in military interventions through a conceptual framework that sustains a historical review of the formation process of the United States Rapid Deployment Force to the National 
Security Strategies of the 1990s. It also deepens the understanding of the logistical and tactical aspects of the military units that make up the military intervention capability of the United States. In conclusion, it points out the utility of such an approach for the policy-making process of the Brazilian Defense Policy.

Palavras-chave: Intervenção Militar, Operações Expedicionárias, Estados Unidos Key words: Military Intervention, Expeditionary Operations, United States 